\title{
Caracterização de Estirpes de Ralstonia solanacearum Isoladas de Plantas de Batata com Murcha Bacteriana, por PCR-Rep e RAPD*
}

\author{
José R. P. Silveira ${ }^{1}$, Valmir Duarte², Marcelo G. Moraes², Andréia M. R. Oliveira, \\ Valmor Barni ${ }^{4} \&$ João L. N. Maciel ${ }^{5}$
}

${ }^{1}$ Fundação Estadual de Pesquisa Agropecuária (FEPAGRO), Rua Gonçalves Dias, 570, CEP 90130-060, Porto Alegre, RS; ${ }^{2}$ Depto. de Fitossanidade, Faculdade de Agronomia, Universidade Federal do Rio Grande do Sul (UFRGS), Cx. Postal 15.100, CEP 90001-970, Porto Alegre, RS, e-mail: valmir@ufrgs.br; ${ }^{3}$ Depto. de Microbiologia, Instituto de Ciências Básicas da Saúde, UFRGS, Rua Sarmento Leite 500, CEP 90050-170, Porto Alegre, RS; ${ }^{4}$ Centro de Pesquisa de Agroindústria, FEPAGRO, Cx. Postal 172, CEP 95100-970, Caxias do Sul, RS; ${ }^{5}$ Embrapa Trigo, Cx. Postal 451, CEP 99001-970, Passo Fundo, RS

(Aceito para publicação em 13/07/2005)

Autor para correspondência: Valmir Duarte

SILVEIRA, J.R.P., DUARTE, V., MORAES, M.G., OLIVEIRA, A.M.R., BARNI, V. \& MACIEL, J.L.N. Caracterização de estirpes de Ralstonia solanacearum isoladas de plantas de batata com murcha bacteriana, por PCR-rep e RAPD. Fitopatologia Brasileira 30:615-622. 2005.

\section{RESUMO}

Considerado como um dos mais sérios patógenos da batata (Solanum tuberosum), em regiões de clima tropical, subtropical, assim como em zonas mais quentes de clima temperado, Ralstonia solanacearum é uma espécie com significativa diversidade genética. Ela é caracterizada em um sistema binário de raças e biovares, com base nas espécies hospedeiras e na capacidade de utilizar diferentes fontes de carbono. A tentativa de utilizar a resistência genética como forma de controle de $R$. solanacearum não tem demonstrado estabilidade, devido a alterações climáticas nas diferentes regiões e a variabilidade das estirpes do patógeno. Devido às características epidemiológicas diferentes para essas biovares, estirpes da biovar 2 são mais factíveis de serem erradicadas em um sistema de controle integrado. Em um levantamento realizado em quatro regiões produtoras de batata do Rio Grande do Sul, foram obtidos isolados de $R$. solanacearum de 25 lavouras de dez municípios. Após a análise bioquímica dos isolados verificou-se a presença das biovares $1 \mathrm{e} 2$, com predominância da última. Os isolados obtidos foram submetidos à avaliação da variabilidade genética por PCR, utilizando sequiências repetitivas ERIC e BOX e oligonucleotídeos aleatórios (RAPD). A PCR-ERIC e BOX puderam diferenciar claramente as biovares 1 e 2. Porém, ambas não detectaram variabilidade entre isolados da biovar 2 e apenas PCR-BOX detectou variabilidade entre isolados da biovar 1. Já através de RAPD demonstrou-se claramente a separação das biovares verificando-se que os mesmos apresentam um perfil característico dependente da região da qual os isolados foram obtidos.

Palavras-chave adicionais: variabilidade genética, ERIC, BOX, biovar, raça.

\begin{abstract}
Characterization of strains of Ralstonia solanacearum isolated from potato plants with bacterial wilt by rep-PCR and RAPD

Considered one of the most important potato (Solanum tuberosum) pathogens in tropical and subtropical regions, as well as in temperate regions with warmer climate, Ralstonia solanacearum is a species with significant genetic diversity. It has been characterized in a binary system of races and biovars based on the range of host species and on the ability to use carbon sources. The attempts to use genetic resistance as a strategy to control $R$. solanacearum were shown to be unstable due to climatic changes in different regions and due to the variability of the pathogenic strains. Due to different epidemiological characteristics of the biovars, strains of biovar 2 are more likely to be eradicated in an integrated control system. In a survey performed in four regions where potato is produced in Rio Grande do Sul, isolates of $R$. solanacearum were obtained from 25 crop fields in ten municipalities. The biochemical analyses of the isolates revealed the occurrence of biovars 1 and 2, the latter being predominant. The isolates obtained were evaluated for their genetic variability by PCR, using repetitive sequences ERIC and BOX and random primers (RAPD). The PCR-ERIC and BOX were able to clearly differentiate the biovars 1 and 2. However, neither analysis was able to demonstrate variability among isolates of biovar 2 and only PCR-BOX showed some degree of variability among isolates of biovar 1 . The amplification by RAPD demonstrates the distinction between the biovars and revealed that they show characteristic profiles that are closely related to the region where they were obtained.
\end{abstract}

Additional keywords: genetic variability, ERIC, BOX, biovar, race.

\section{INTRODUÇÃO}

Ralstonia solanacearum (Smith) Yabuuchi et al. (sin. Pseudomonas solanacearum Smith) é uma espécie complexa

*Parte da Tese de Doutorado do primeiro autor apresentada a Universidade Federal do Rio Grande do Sul (UFRGS) (2002) com significativa diversidade genética (Martins, 2000). Possui um número extensivo de espécies hospedeiras abrangendo mais de 50 famílias botânicas. Nenhuma outra espécie de bactéria fitopatogênica, à exceção de Agrobacterium tumefaciens (Smith \& Townsend) Conn., infeta tamanha diversidade de hospedeiras quanto $R$. 
solanacearum (Hayward, 1995). Para caracterizar esta variabilidade intra-específica utiliza-se um sistema de classificação binário de raças e biovares, embora este não faça parte dos critérios do Código Internacional de Nomenclatura de Bactérias (Buddenhagen et al., 1962; Hayward, 1991). Ralstonia solanacearum pode ser classificada em cinco raças com base nas espécies hospedeiras e em cinco biovares de acordo com a capacidade de utilizar diferentes açúcares e álcoois (He et al., 1983; Hayward, 1994).

Tradicionalmente considerado como um dos mais sérios patógenos da batata (Solanum tuberosum L.) em regiões tropicais e subtropicais de todo o mundo, $R$. solanacearum tem aumentado sua importância após os recentes surtos registrados na Europa (Elphinstone et al., 1996).

A utilização de cultivares resistentes é a alternativa mais simples e efetiva para o controle da murcha bacteriana (Hayward, 1991). No entanto, a resistência genética não tem demonstrado estabilidade em relação ao tempo e ao local, devido às alterações climáticas nas diferentes regiões geográficas e a variabilidade genética das estirpes do patógeno (Grimault et al., 1994). Um maior conhecimento da genética populacional de $R$. solanacearum poderia auxiliar na compreensão da resistência específica a determinados locais (Jaunet \& Wang, 1998). Estudos epidemiológicos dependem do conhecimento da população do patógeno, sendo um prérequisito essencial para o desenvolvimento de estratégias de controle (Smith et al., 1995; Van Der Wolf et al., 1998).

Técnicas moleculares têm permitido o estudo do relacionamento filogenético e evolucionário de $R$. solanacearum, bem como o de variabilidade em nível intraespecífico. Com base em análises de "Restriction Fragment Length Polymorphism" (RFLP), Cook et al. (1989) e Gillings \& Fahy (1993) definiram 33 grupos ou genótipos de $R$. solanacearum. Os coeficientes de similaridade gerados entre os grupos revelaram duas divisões distintas, que refletem um provável relacionamento filogenético ou evolucionário, sendo a origem geográfica das estirpes a característica mais fortemente correlacionada.

No Rio Grande do Sul, Silveira et al. (2002) constataram a ocorrência das biovares 1 e 2 de $R$. solanacearum em áreas de cultivo de batata, em dez municípios diferentes das quatro áreas de produção: Serra do Nordeste, Planalto Superior, Depressão Central e Grandes Lagoas. A predominância foi de $94 \%$ de isolados da biovar 2, sem haver relação com a temperatura média local ou cultivar de batata.

O objetivo deste trabalho foi caracterizar isolados das biovares 1 e 2 de $R$. solanacearum provenientes das quatro regiões produtoras de batata no Estado do Rio Grande do Sul, utilizando marcadores PCR-ERIC, BOX e RAPD.

\section{MATERIAL E MÉTODOS}

\section{Obtenção dos isolados de $R$. solanacearum}

Os isolados foram obtidos de plantas de batata com sintomas de murcha bacteriana, coletadas nos meses de setembro a dezembro de 1999, em 25 lavouras localizadas em dez municípios de quatro regiões produtoras do Estado do Rio Grande do Sul: Depressão Central (Santa Maria e Silveira Martins); Serra do Nordeste (Carlos Barbosa, Farroupilha e Garibaldi); Planalto Superior (Nova Prata, Ibiraiáras e São Jorge) e Grandes Lagoas (Pelotas e São Lourenço) (Tabela 1).

$\mathrm{O}$ isolamento foi realizado através da coleta do fluxo bacteriano em tubos de microcentrífuga, contendo $0,5 \mathrm{ml}$ de água destilada esterilizada (ADE), a partir de segmentos de hastes de 1 a $2 \mathrm{~cm}$ previamente desinfestados com $\mathrm{NaOCl}$ $1 \%$ e ADE. A suspensão de células foi diluída em série (10x) por transferência para novos tubos com ADE e $20 \mu \mathrm{l}$ das diferentes diluições foram espalhados por esgotamento na superfície do meio de cultura SPA (sacarose $20 \mathrm{~g} . \mathrm{l}^{-1}$; peptona 5 g. $1^{-1} ; \mathrm{K}_{2} \mathrm{HPO}_{4} 0,5$ g..$^{-1} ; \mathrm{MgSO}_{4} .7 \mathrm{H}_{2} \mathrm{O} 0,25$ g..$^{-1}$; Agar 15 g. $\left.1^{-1}\right) \mathrm{pH} 7,2$ (Hayward, 1960), contendo $0,05 \%$ de cloreto de trifenil tetrazólio. Colônias fluídas com centro vermelho e bordas brancas foram transferidas para novas placas contendo SPA e, após $48 \mathrm{~h}$ a $28^{\circ} \mathrm{C}$, submetidas aos testes de Gram, oxidase e "Double antibody sandwich- Enzyme linked immunosorbent assay" (DAS-ELISA), com anti-soro policlonal reativo a $R$. solanacearum fornecido pela Embrapa de Clima Temperado (Castro et al., 1993). Os isolados obtidos, um por planta, foram então submetidos a testes bioquímicos para determinação da biovar, de acordo com a capacidade em oxidar as fontes de carbono: celobiose, lactose, maltose, trealose, dulcitol, manitol e sorbitol, conforme Schaad (1988). Os isolados foram armazenados em ADE a $5{ }^{\circ} \mathrm{C}$ e em glicerol-água $(15: 85)$ à $-80{ }^{\circ} \mathrm{C}$.

Os isolados de referência para as biovares 1 e 2 de $R$. solanacearum utilizados neste estudo foram fornecidos pela Embrapa de Clima Temperado: isolados RS6, RS7 e RS45 (biovar 2), isolados RS25 e RS26 (biovar 1) e pela Embrapa Hortaliças: isolado RS44 (biovar 2), isolados RS72, RS116 e RS127 (biovar 1). Todos os isolados fornecidos são oriundos de plantas de batata e caracterizados nos respectivos centros de pesquisa.

\section{PCR-BOX, ERIC e RAPD}

A extração do DNA dos isolados de $R$. solanacearum foi realizada de acordo com Boucher et al. (1987), as quantificações realizadas em espectrofotômetro (Beckman DU 65) e as amostras mantidas a $-20{ }^{\circ} \mathrm{C}$. A variabilidade genética dos isolados foi avaliada para as seqüências repetitivas ERIC e BOX, utilizando os oligonucleotídeos iniciadores ERIC1R (5' ATG TAA GCT CCT GGG GAT TCA C3') e ERIC2 (5'AAG TAA GTG ACT GGG GTG AGC G3') e BOXA1R (5'CTA CGG CAA GGC GAC GCT GAC G3') (Annovis). A PCR foi realizada em termociclador MJ Research (Minicycler TM) em 25 ìl, contendo solução tampão de PCR (10 mM Tris- $\mathrm{HCl}[\mathrm{pH} 8,3], 50 \mathrm{mM} \mathrm{KCl}$ ); $1,5 \mathrm{mM} \mathrm{MgCl}_{2}$ (BOX); $2 \mathrm{mM} \mathrm{MgCl}$ (ERIC); 0,2 mM de deoxinucleotídeos (cada); 1,25 U polimerase AmpliTaq (Gibco-BRL); 1 ìM dos oligonucleotídeos iniciadores e 60 
ng de DNA. As condições foram 5 min a $95^{\circ} \mathrm{C} ; 30$ ciclos $[1$ $\min$ a $94{ }^{\circ} \mathrm{C}, 1 \mathrm{~min}$ a $51^{\circ} \mathrm{C}(\mathrm{BOX})$ e $53{ }^{\circ} \mathrm{C}($ ERIC), 8 min a $65^{\circ} \mathrm{C}$ ] e $15 \min$ a $65^{\circ} \mathrm{C}$.

A PCR-RAPD foi realizada com o conjunto OPO de oligonucleotídeos iniciadores OPO-02 (5'ACG TAG CGT C3'); OPO-04 (5'AAG TCC GCT C3'); OPO-10 (5'TCA GAG CGC C3') e OPO-12 (5'CAG TGC TGT G3') (Operon Technologies Inc. USA). As reações foram realizadas no mesmo termociclador utilizado para as análises de PCRrep, em um volume de 25 ìl, contendo solução tampão de PCR (10 mM Tris-HCl [pH8,3], $50 \mathrm{mM} \mathrm{KCl);} 2$ mM de $\mathrm{MgCl}_{2 ;}, 0,001 \%$ de gelatina; $0,2 \mathrm{mM}$ de deoxinucleotídeos (cada); 1,25 U polimerase AmpliTaq (Gibco-BRL); 10 picomoles de cada um dos oligonucleotídeos iniciadores e 60 ng de DNA. As condições foram 5 min a $94{ }^{\circ} \mathrm{C} ; 40$ ciclos $(1$ $\min$ a $94{ }^{\circ} \mathrm{C}, 1 \min$ a $38{ }^{\circ} \mathrm{C}, 2 \min$ a $72{ }^{\circ} \mathrm{C}$ ) e $10 \min$ a $72{ }^{\circ} \mathrm{C}$.

Os produtos resultantes da amplificação da PCRRAPD, ERIC e BOX foram separados em gel de agarose $1,4 \%$, submetidos à eletroforese $4 \mathrm{~V} / \mathrm{cm}$ por $4 \mathrm{~h}$, corados com brometo de etídio $(0,05 \%)$, visualizados sob luz ultravioleta e fotografados com sistema de fotodocumentação computadorizado de análise de gel (Kodak Digital Science 1D - EDAS 120). Os dados foram analisados pelo programa estatístico NTSYS (Numerical Taxonomy System), onde foi determinada a matriz de similaridades genéticas e construído o dendrograma. A matriz de similaridade genética entre os isolados foi construída utilizando o coeficiente Jaccard e os agrupamentos feitos de acordo com o método UPGMA (Unweight Pair Group Method with Arithmetic Average) (Crisci \& Armengol, 1983).

\section{RESULTADOS E DISCUSSÃO}

Os isolados obtidos foram reativos ao anti-soro policlonal de $R$. solanacearum e resultaram positivos pelo teste de oxidase e Gram negativos. Isolados que utilizaram os açúcares lactose, maltose e celobiose, e não utilizaram as demais fontes de carbono, foram considerados como biovar 2. Os isolados da biovar 1 utilizaram apenas trealose (Tabela 1).

A amplificação por PCR do DNA das estirpes de $R$. solanacearum obtidos em áreas de produção de batata no Rio Grande do Sul, utilizando oligonucleotídeos iniciadores para sequiências ERIC e BOX, produziu múltiplos produtos com tamanho variando de 0,2 a $3 \mathrm{~kb}$, resultando em perfis genéticos distintos (Figuras 1 e 2). A PCR-BOX produziu um número superior de fragmentos amplificados, quando comparado com ERIC, porém, ambos puderam diferenciar claramente os isolados das biovares 1 e 2 .

Dois segmentos resultantes da amplificação do DNA dos isolados da biovar 1 (480 e 760 pb) e três segmentos para os isolados da biovar $2(610,690$ e 1400 pb), utilizando ERIC, permitiram a caracterização e a separação das duas biovares com este marcador (Figura 1). Os fragmentos obtidos através de BOX mantiveram um padrão distinto para os isolados da biovar 2 , com um número significativo de segmentos característicos $(450,560,790,1000,1100$ e 1310 pb), mesmo para os isolados de referência (Figura 2). No entanto, comportamento diferente foi verificado para os isolados da biovar 1 analisados com seqüências BOX. Os isolados da biovar 1 não reproduziram um padrão distinto com este marcador, demonstrando maior variabilidade genética. Os isolados de lavouras do município de Garibaldi puderam ser diferenciados dos isolados de Silveira Martins, bem como dos isolados de referência, o que demonstra a maior capacidade deste marcador em revelar polimorfismos existentes, notadamente a maior variabilidade entre isolados da biovar 1 .

Os isolados da biovar 2 não apresentaram variabilidade genética com as sequiências ERIC e BOX, embora tenham amplificado um maior número de fragmentos reproduzíveis (Figuras 1 e 2). Resultados semelhantes foram relatados por Van Der Smith et al. (1995) e Wolf et al. (1998). Segundo Van Der Wolf et al. (1998), o conjunto de oligonucleotídeos iniciadores ERIC e BOX puderam diferenciar isolados de diferentes biovares, porém, foram incapazes de diferenciar isolados da biovar 2 (raça 3). Esta homogeneidade para as estirpes da biovar 2 foi demonstrada por outras técnicas. Gillings \& Fahy (1993) definiram por análises de RFLP, 33 grupos ou genótipos de $R$. solanacearum. Os isolados da biovar 2, com centro de origem na região Andina Ocidental, foram incorporados a apenas dois grupos RFLP (26 e 27), bastante homogêneos e geneticamente muito similares, enquanto que os isolados da biovar 1 foram dispostos em seis grupos de RFLP geneticamente heterogêneos. De acordo com Smith et al. (1998), há uma correlação entre a variabilidade genética e o número de espécies hospedeiras. Para $R$. solanacearum biovar 2, as espécies hospedeiras se restringem quase que exclusivamente à batata e em menor extensão ao tomateiro (Lycopersicon esculentum Mill.), enquanto que, a biovar 1 apresenta uma diversidade de espécies hospedeiras.

A variabilidade entre isolados da biovar 2 tem sido mais apropriadamente determinada por "Pulsed-Field Gel Electrophoresis" (PFGE). Smith et al. (1995) determinaram dez distintas linhas clonais entre 45 isolados da biovar 2 , obtidos em áreas de produção de batata no Quênia por PFGE. De acordo com Van Der Wolf et al. (1998), os recentes surtos de murcha bacteriana registrados na Europa tornaram necessário o conhecimento da variação na população do patógeno, como base para estudos epidemiológicos visando medidas de controle. Embora os autores não tenham obtido êxito com PCR-BOX e ERIC para estirpes da biovar 2 (raça 3), a diversidade encontrada com "Amplified fragmentlength polymorphism" (AFLP) e PFGE, este último utilizando enzima de restrição XbaI, permitiu separar as estirpes desta biovar em diversos grupos, indicando a presença de diferentes linhas clonais na Europa. Mesmo para isolados das biovares 1 e 3 (raça 1), que apresentam maior variabilidade, como demonstrado por PCR-BOX e ERIC, trabalhos como o de Frey et al. (1996), confirmam que a técnica de PFGE é mais discriminatória. 
J.R.P. Silveira et al.

TABELA 1 - Biovares de Ralstonia solanacearum obtidos de plantas de batata (Solanum tuberosum) de lavouras das diferentes regiões produtoras do RS e avaliados por PCR-ERIC, BOX e RAPD

\begin{tabular}{|c|c|c|c|c|c|c|c|c|c|}
\hline Sub Região & Município & Isolado* & Biovar & $\begin{array}{l}\text { Cultivar } \\
\text { de Batata }\end{array}$ & Sub Região & Município & Isolado * & Biovar & $\begin{array}{l}\text { Cultivar } \\
\text { de Batata }\end{array}$ \\
\hline \multirow{38}{*}{$\begin{array}{l}\text { Serra do } \\
\text { Nordeste }\end{array}$} & \multirow[t]{11}{*}{ Carlos Barbosa } & $\mathrm{CB} 12$ & 2 & Sinfonia & Planalto & \multirow[t]{9}{*}{ Ibirai aras } & IB13 & 2 & Elvira \\
\hline & & CB13 & 2 & Sinfonia & Superior & & IB16 & 2 & Elvira \\
\hline & & CB16 & 2 & Sinfonia & & & IB18 & 2 & Elvira \\
\hline & & CB112 & 1 & Sinfonia & & & IB22 & 2 & Baronesa \\
\hline & & CB116 & 1 & Sinfonia & & & IB24 & 2 & Baronesa \\
\hline & & CB22 & 2 & Baronesa & & & IB26 & 2 & Baronesa \\
\hline & & $\mathrm{CB} 23$ & 2 & Baronesa & & & IB31 & 2 & Macaca \\
\hline & & $\mathrm{CB} 25$ & 2 & Baronesa & & & IB32 & 2 & Macaca \\
\hline & & CB32 & 2 & Baronesa & & & IB34 & 2 & Macaca \\
\hline & & CB33 & 2 & Baronesa & & \multirow[t]{9}{*}{ Nova Prata } & NP13 & 2 & Baronesa \\
\hline & & CB38 & 2 & Baronesa & & & NP16 & 2 & Baronesa \\
\hline & \multirow[t]{7}{*}{ Farroupilha } & FA11 & 2 & Elvira & & & NP18 & 2 & Baronesa \\
\hline & & FA13 & 2 & Elvira & & & NP23 & 2 & Asterix \\
\hline & & FA15 & 2 & Elvira & & & NP210 & 2 & Asterix \\
\hline & & FA118 & 1 & Elvira & & & NP211 & 2 & Asterix \\
\hline & & FA21 & 2 & Baronesa & & & NP32 & 2 & Baronesa \\
\hline & & FA2 2 & 2 & Baronesa & & & NP34 & 2 & Baronesa \\
\hline & & FA24 & 2 & Baronesa & & & NP37 & 2 & Baronesa \\
\hline & \multirow[t]{20}{*}{ Garibaldi } & GA11 & 1 & Sinfonia & & \multirow[t]{9}{*}{ Sao Jorge } & SJ15 & 2 & Baronesa \\
\hline & & GA1 2 & 1 & Sinfonia & & & SJ16 & 2 & Baronesa \\
\hline & & GA13 & 1 & Sinfonia & & & SJ19 & 2 & Baronesa \\
\hline & & GA14 & 1 & Sinfonia & & & SJ26 & 2 & Baronesa \\
\hline & & GA15 & 1 & Sinfonia & & & SJ212 & 2 & Baronesa \\
\hline & & GA16 & 1 & Sinfonia & & & SJ215 & 2 & Baronesa \\
\hline & & GA17 & 1 & Sinfonia & & & SJ37 & 2 & Baronesa \\
\hline & & GA18 & 1 & Sinfonia & & & SJ310 & 2 & Baronesa \\
\hline & & GA19 & 1 & Sinfonia & & & SJ317 & 2 & Baronesa \\
\hline & & GA110 & 1 & Sinfonia & \multirow{11}{*}{$\begin{array}{l}\text { Depressão } \\
\text { Central }\end{array}$} & \multirow[t]{9}{*}{ Santa Maria } & ST11 & 2 & Baronesa \\
\hline & & GA111 & 1 & Sinfonia & & & ST11 2 & 2 & Bar onesa \\
\hline & & GA112 & 1 & Sinfonia & & & ST 118 & 2 & Baronesa \\
\hline & & GA113 & 1 & Sinfonia & & & ST21 & 2 & Baronesa \\
\hline & & GA114 & 1 & Sinfonia & & & ST25 & 2 & Baronesa \\
\hline & & GA115 & 1 & Sinfonia & & & ST21 6 & 2 & Baronesa \\
\hline & & GA116 & 1 & Sinfonia & & & ST33 & 2 & Macaca \\
\hline & & GA117 & 1 & Sinfonia & & & ST35 & 2 & Macaca \\
\hline & & GA118 & 1 & Sinfonia & & & ST37 & 2 & Macaca \\
\hline & & GA119 & 1 & Sinfonia & & \multirow{14}{*}{$\begin{array}{l}\text { Silveira } \\
\text { Martins }\end{array}$} & SM1 2 & 2 & Elvira \\
\hline & & GA120 & 1 & Sinfonia & & & SM14 & 2 & Elvira \\
\hline \multirow{12}{*}{$\begin{array}{l}\text { Grandes } \\
\text { Lagoas }\end{array}$} & \multirow[t]{3}{*}{ Pelotas } & PE11 & 2 & Macaca & & & SM16 & 2 & Elvira \\
\hline & & PE18 & 2 & Macaca & & & SM22 & 2 & Macaca \\
\hline & & PE110 & 2 & Macaca & & & SM23 & 2 & Macaca \\
\hline & \multirow{9}{*}{$\begin{array}{l}\text { Sao Lourenço } \\
\text { do Sul }\end{array}$} & SL14 & 2 & Macaca & & & SM25 & 2 & Macaca \\
\hline & & SL16 & 2 & Macaca & & & SM31 & 2 & Macaca \\
\hline & & SL18 & 2 & Macaca & & & SM33 & 1 & Macaca \\
\hline & & SL24 & 2 & Sinfonia & & & SM3 5 & 2 & Macaca \\
\hline & & SL26 & 2 & Sinfonia & & & SM36 & 1 & Macaca \\
\hline & & SL27 & 2 & Sinfonia & & & SM37 & 1 & Macaca \\
\hline & & SL32 & 2 & SantoAmor & & & SM38 & 2 & Macaca \\
\hline & & SL34 & 2 & SantoAmor & & & SM316 & 1 & Macaca \\
\hline & & SL35 & 2 & SantoAmor & & & SM319 & 1 & Macaca \\
\hline
\end{tabular}

*um por planta 
Trabalhos biogeográficos com PCR-rep indicam que, na América do Sul, as estirpes de $R$. solanacearum biovar 2A compreendem três linhas clonais, uma no Peru, outra na Colômbia e Chile e uma terceira nos demais países da América do Sul (Smith et al., 1998). A biovar 2T, com centro de origem na região Amazônica, está relacionada a regiões de clima tropical de baixa altitude, possui um grande número de espécies hospedeiras e não é equivalente a biovar 2 (raça 3) (Horita \& Tsuchiya, 2001). Apesar de sua aparência fenotípica bastante homogênea, é composta pelos grupos RFLP de 29 a 32, que são geneticamente heterogêneos (Gillings \& Fahy, 1993).

A amplificação do DNA por RAPD das estirpes de $R$. solanacearum a partir de oligonucleotídeos iniciadores OPO-10 produziu múltiplos produtos, com tamanho variando de 0,2 a $3 \mathrm{~kb}$ (Figura 3). Os demais oligonucleotídeos iniciadores OPO-2, OPO-4 e OPO-12 produziram um número limitado de fragmentos (dados não apresentados)

\section{$\begin{array}{llllllllllllllll}M & 1 & 2 & 3 & 4 & 5 & 6 & 7 & 8 & 9 & 10 & 11 & 12 & 13 & 14 & 15\end{array}$}

$1400 \mathrm{pb} \rightarrow$

$\leftarrow 760 \mathrm{pb}$

$690 \mathrm{pb} \rightarrow$

$610 \mathrm{pb} \rightarrow$

$\leftarrow 480 \mathrm{pb}$

FIG. 1 - Produto da amplificação do DNA de isolados de Ralstonia solanacearum por PCR-ERIC. (M) Marcador de peso molecular $1 \mathrm{~kb}$, Isolados da biovar 2: (1) Isolado CB12, (2) CB16, (3) IB13, (4) IB18, (5) SL14, (6) SL16, (7) NP23, (8) NP37, (9) isolado de referência RS45, Isolados da biovar 1: (10) GA11, (11) GA17, (12) SM37, (13) SM316, (14) Isolados de referência RS72 e (15) Controle Negativo.

\section{$\begin{array}{llllllllllllllllll}M & 1 & 2 & 3 & 4 & 5 & 6 & 7 & 8 & 9 & 10 & 11 & 12 & 13 & 14 & 15 & 16 & 17\end{array}$}

$$
\begin{aligned}
& 1310 \mathrm{pb} \rightarrow \\
& 1100 \mathrm{pb} \rightarrow \\
& 1000 \mathrm{pb} \rightarrow \\
& 790 \mathrm{pb} \rightarrow \\
& 560 \mathrm{pb} \rightarrow \\
& 450 \mathrm{pb} \rightarrow
\end{aligned}
$$

FIG. 2 - Produto da amplificação do DNA de isolados de Ralstonia solanacearum por PCRBOX. (M) Marcador de peso molecular $1 \mathrm{~kb}$, Isolados da biovar 2: (1) Isolado FA13, (2) FA15, (3) ST33, (4) ST35, (5) PE11, (6) PE18, (7) SJ15, (8) SJ26, (9) isolado de referência RS45, Isolados da biovar 1: (10) GA11, (11) GA17, (12) SM37, (13) SM316, (14) Isolados de referência RS127, (15) RS72, (16) RS116 e (17) Controle Negativo. 
e não foram utilizados nas análises de similaridade genética e agrupamento para a construção do dendrograma.

O padrão de eletroforese do DNA dos isolados demonstrou que os mesmos apresentam um perfil de amplificação característico, bastante relacionado com a região da qual os isolados foram obtidos apresentando, no entanto, pouca variabilidade entre os isolados do mesmo local. A análise de agrupamento com os dados obtidos com os oligonucleotídeos iniciadores OPO-10 separou as estirpes das biovares 1 e 2 em dois grupos distintos (Figura 4). A similaridade entre as estirpes da biovar 1 foi superior a $7 \%$ e a $25 \%$ ente as estirpes da biovar 2 .

Trabalhos utilizando marcadores moleculares RAPD têm sido realizados para a detecção de $R$. solanacearum (Salava et al., 1998; Lee \& Wang, 2000), bem como para o melhoramento genético visando a resistência (Yui et al., 1999; Fock et al., 2000, Gao et al., 2000).

O potencial da técnica de RAPD para determinação de diversidade genética de $R$. solanacearum também tem sido demonstrada (Jaunet \& Wang, 1998; Thwaites et al., 1999). Ito et al. (1996) investigaram a variabilidade genética de isolados de nove diferentes áreas agrícolas do Japão por RAPD e análise de restrição e concluíram que a população de $R$. solanacearum consistia de um número independente de linhas clonais, sendo as mesmas relacionadas à região de origem. Do mesmo modo, Jaunet et al. (1996) verificaram elevada variabilidade entre isolados obtidos de viveiros de produção de mudas e de campos de produção de tomate em Taiwan. De acordo com Jaunet \& Wang (1998), o método
RAPD demonstrou a diversidade genética da população de $R$. solanacearum biovares 3 e 4 dos campos de produção de tomate, em um nível muito mais elevado do que os determinados por PFGE em isolados da biovar 2 (raça 3) por Smith et al. (1995) e de isolados das biovares 1 e 3 (raça 1) por Frey et al. (1996).

No presente trabalho a similaridade entre os isolados foi bastante reduzida com os oligonucleotídeos utilizados (similaridade pouco acima de $20 \%$ para isolados da biovar 2 e abaixo de $10 \%$ para isolados da biovar 1). Jaunet \& Wang (1998) utilizaram os oligonucleotídeos iniciadores da série OPA (Operon Technologies Inc. USA) para caracterizar isolados de $R$. solanacearum de diferentes biovares. Segundo os autores, os oligonucleotídeos OPAD1, OPAG6, OPAG14 e OPAE1 foram selecionados devido a sua capacidade em revelar polimorfismo entre isolados das biovares 3 e 4 de diferentes países asiáticos. Portanto, a capacidade do método RAPD em detectar polimorfismo depende, também, da escolha de oligonucleotídeos iniciadores que possibilitem revelar maior variabilidade entre os isolados da biovar em estudo.

Embora tenha sido possível diferenciar as biovares 1 e 2 de $R$. solanacearum utilizando marcadores PCR-rep e RAPD, a dificuldade em acessar a variabilidade entre os isolados de cada biovar sugere a necessidade de estudos utilizando marcadores como AFLP ou PFGE, os quais têm demonstrado serem mais eficientes na determinação da variabilidade genética das biovares 1 e 2 (Smith et al., 1995; Van Der Wolf, 1998).

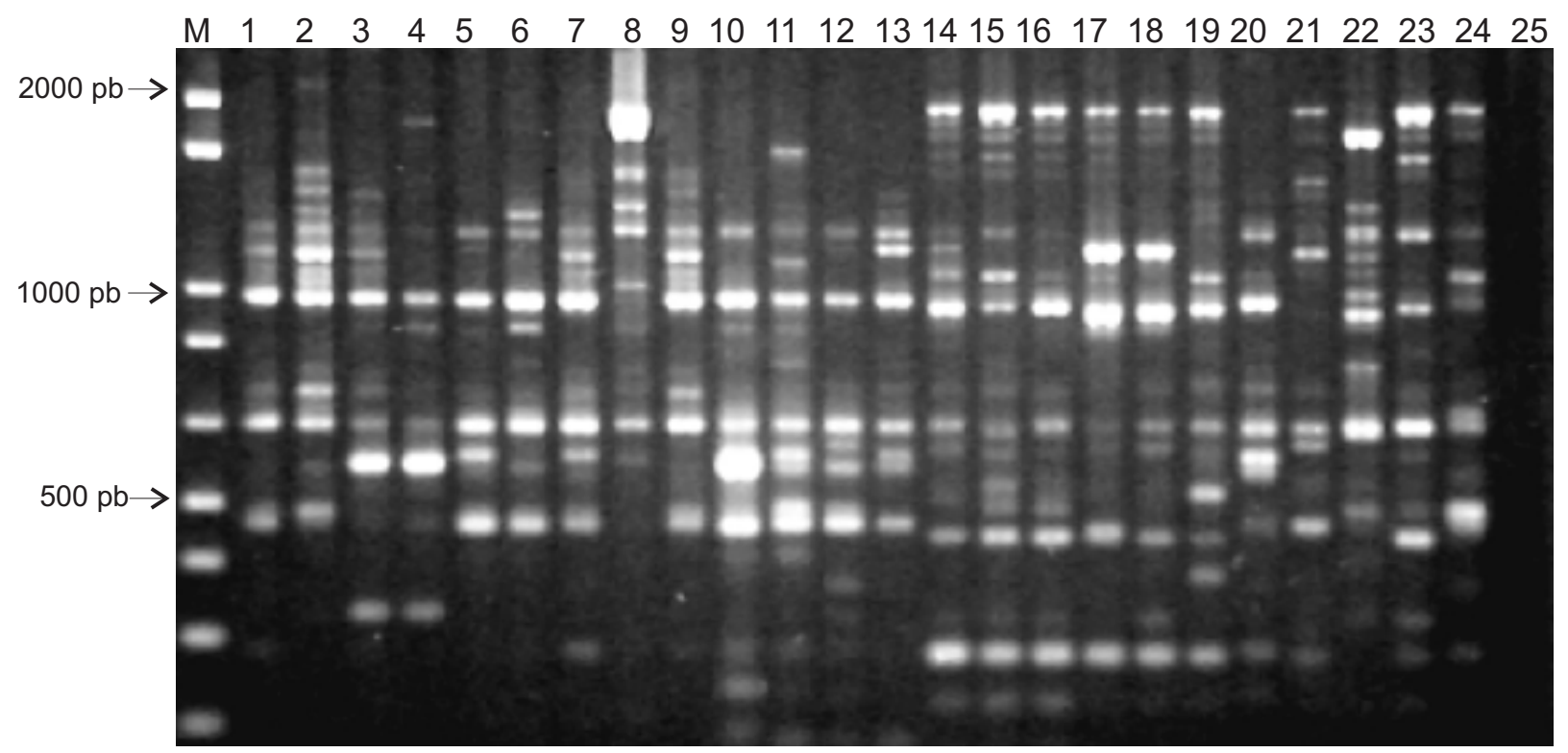

FIG. 3 - Produto da amplificação do DNA de isolados de Ralstonia solanacearum por PCR-RAPD. (M) Marcador de peso molecular 1 kb, Isolados da biovar 2: (1) Isolado PE11, (2) PE18, (3) ST25, (4) ST216, (5) SL16, (6) SL18, (7) NP16, (8) NP34, (9) NP32, (10) IB13, (11) IB22, (12) SJ15, (13) SJ26, Isolados da biovar 1: (14) GA14, (15) GA18, (16) GA110, (17) GA17, (18) CB112, (19) SM316, (20) Isolados de referência RS6, (21) RS26, (22) RS72, (23) RS127, (24) RS116 e (25) Controle Negativo. 
Caracterização de estirpes de Ralstonia solanacearum isoladas de plantas de batata...

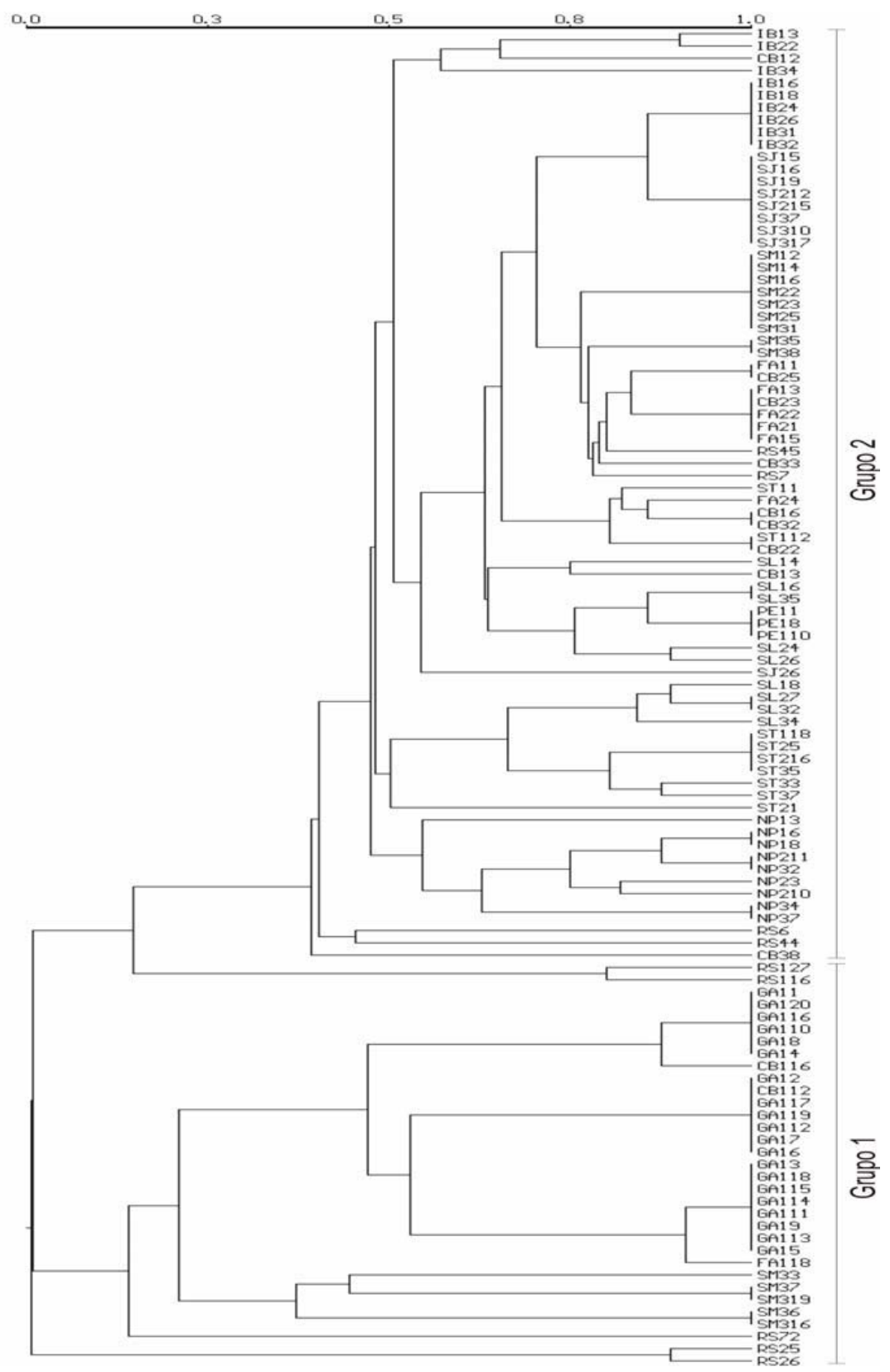

FIG. 4 - Dendrograma baseado no método UPGMA, de acordo com perfis de amplificação gerado por PCRRAPD dos isolados de Ralstonia solanacearum obtidos de lavouras de produção de batata (Solanum tuberosum) no RS. ST (Santa Maria), FA (Farroupilha), SM (Silveira Martins), CB (Carlos Barbosa), SJ (São Jorge), IB (Ibiraiáras), NP (Nova Prata), SL (São Lourenço), PE (Pelotas), GA (Garibaldi), RS (Isolados de Referência).

\section{REFERÊNCIAS BIBLIOGRÁFICAS}

BOUCHER C.A., VAN GIJSEGEM, F., BARBERIS, P.A., ARLAT, M. \& ZISCHEK, C. Pseudomonas solanacearum genes controlling both pathogenicity on tomato and hipersensitivity on tobacco are clustered. Journal of Bacteriology 169:5626-5632. 1987.

BUDDENHAGEN, I., SEQUEIRA, L. \& KELMAN, A. Designation of races in Pseudomonas solanacearum. Phytopathology 52:726.
1962. (Abstract).

CASTRO, L.A.S., DANIELS, J. \& COUTO, M.E.O. Utilização do teste de ELISA na diagnose de Pseudomonas solanacearum. Fitopatologia Brasileira 18:296. 1993. (Resumo).

COOK, D., BARLOW, E. \& SEQUEIRA, L. Genetic diversity of Pseudomonas solanacearum: detection of restriction fragment length polymorphisms with DNA probes that specify virulence and the hypersensitive response. Molecular Plant-Microbe Interaction 


\section{2:113-121. 1989.}

CRISCI, J.V. \& ARMENGOL, M.F.L. Introduction a la teoria practica de la taxonomia numerica. Washington. Secretaria General de la Organización de los Estado Americanos. 1983.

ELPHINSTONE, J.G., HENNESSY, J., WILSON, J.K. \& STEAD, D.E. Sensitivity of different methods for the detection of Ralstonia solanacearum in potato tuber extracts. EPPO Bulletin 26:663-678. 1996.

FOCK, I., COLLONNIER, C., PURWITO, A., LUISETTI, J., SOUVANNAVONG, V., VEDEL, F., SERVAES,A., AMBROISE, A., KODJA, H., DUCREUX, G. \& FREY, P., SMITH, J.J., ALBAR, L., PRIOR, P., SADDLER, G.S., TRIGALET-DEMERY, D. \& TRIGALET, A. Bacteriocin typing of Burkholderia (Pseudomonas) solanacearum race 1 of the French West Indies and correlation with genomic variation of the pathogen. Applied and Environmental Microbiology 62:473-479. 1996.

GAO, G., QU, D.Y., LIAN, Y., JIN, L. \& FENG, L. Identification molecular markers linked with resistance to bacterial wilt (Ralstonia solanacearum) in diploid potato. Acta Horticulturae Sinica 27:3741. 2000.

GILLINGS, M. \& FAHY, P. Genomic fingerprinting and PCR analysis: rapid, sensitive and inexpensive means of differentiating strains of Pseudomonas solanacearum. In: Hartman, G.L. \& Hayward, A.C. (Eds.) Bacterial Wilt. Canberra, ACIAR Proceedings. 1993. pp.85-92.

GRIMAUlT, V., ANAIS, G. \& PRIOR, P. Distribution of Pseudomonas solanacearum in the stem tissues of tomato plants with different levels of resistance to bacterial wilt. Plant Pathology 43:633-668. 1994.

HAYWARD, A.C. Pseudomonas solanacearum. In: Singh, U., Singh, R. \& Kohmoto, K. (Eds.) Pathogenesis and host specificity in plant diseases: Histopathological, biochemical, genetic and molecular bases. Oxford: Pergamon. 1995. pp.139-151.

HAYWARD, A.C. Systematics and phylogeny of Pseudomonas solanacearum and related bacteria. In: Hayward, A.C. \& Hartman, G.L. (Eds.) Bacterial Wilt: The disease and its causative agent, Pseudomonas solanacearum. Wallingford: CAB International, 1994. pp.123-135.

HAYWARD, A.C. Biology and epidemiology of bacterial wilt caused by Pseudomonas solanacearum. Annual Review of Phytopathology 29:65-87. 1991.

HAYWARD, A.C. A method for characterizing Pseudomonas solanacearum. Nature 186:405-406. 1960.

HE, L.Y., SEQUEIRA, L. \& KELMAN. A. Characteristics of strains of Pseudomonas solanacearum from China. Plant Disease 67:13571361. 1983.

HORITA, M. \& TSUCHIYA, K. Genetic diversity of Japanese strains of Ralstonia solanacearum. Phytopathology 91:399-407. 2001.

ITO, S., FUJII, T., USHIJIMA, Y., TANAKA, S., KAMEYA, I.M., YOSHIWARA, S. \& KISHI, F. Genomic diversity of field isolates of Burkholderia solanacearum in Japan. Journal of Phytopathology
144:501-504. 1996.

JAUNET, T. \& WANG, J.F. Population structure of Ralstonia solanacearum from a disease nursery and tomato production fields in Taiwan. In: Prior, P.H., Allen, C. \& Elphinstone, J. (Eds.) Bacterial wilt disease: molecular and ecological aspects. Berlin: Springer Verlang, INRA Reports. 1998. pp.83-88.

JAUNET, T., LEE, J., HSU, C.F. \& WANG, J.F. Genetic diversity of Ralstonia solanacearum, causal agent of tomato bacterial wilt in Taiwan. TVIS Neewsletter 1:20-21. 1996.

LEE, Y. \& WANG, C. The design of specific primers for the detection of Ralstonia solanacearum in soil samples by polymerase chain reaction. Botanical Bulletin of Academia Sinica 2:121-128. 2000.

MARTINS, O.M. Polymerase chain reaction in the diagnosis of bacterial wilt, caused by Ralstonia solanacearum (Smith) Yabuuchi et al. (PhD Thesis) Göttingen, Georg-August University. 2000.

SALAVA, J., BRYXIOVA, M. \& KOKOSKOVA, B. Identification of plant pathogenic bacteria by random polymorphic DNA (RAPD) assay. Plant Protection Science 34:137-141. 1998.

SCHAAD, N.W. Laboratory Guide for Identification of Plant Pathogenic Bactéria. $2^{\text {nd }}$ ed. St Paul. American Phytopathological Society. 1988.

SILVEIRA, J.R.P., DUARTE, V. \& MORAES, M.G. Ocorrência das biovares 1 e 2 de Ralstonia solanacearum em lavouras de batata no Estado do Rio Grande do Sul. Fitopatologia Brasileira 27:450453. 2002.

SMITH, J.J., KIBATA, G.N., NURIMI, Z.K., LUM, K.Y., FERNANDEZ-NORTHCOTE, E., OFFORD, L.C. \& SADDLER, G.S. Biogeographic studies on Ralstonia solanacearum race 1 and 3 by genomic fingerprinting. In: Prior, P., Allen, C. \& Elphinstone, J. (Eds.) Bacterial Wilt Disease: molecular and ecological aspects. Berlin: Springer - Verlang, INRA Reports. 1998. pp.50-55.

SMITH, J.J., OFFORD, L.C., HOLDERNESS, M. \& SADDLER, G.S. Genetic diversity of Burkholderia solanacearum (synonym Pseudomonas solanacearum) race 3 in Kenya. Applied and Environmental Microbiology 61:4263-4268. 1995.

THWAITES, R., MANSFIELD, J., EDEN-GREEN, S \& SEAL, S. RAPD and rep PCR-based fingerprinting of vascular bacterial pathogens of Musa spp. Plant Pathology 48:121-128. 1999.

VAN DER WOLF, J.M., BONANTS, P.J., SMITH, J.J., HAGENAAR, M., NIJHUIS, E., VAN BECKHOVEN, J.R.C.M., SADDLER, G.S., TRIGALET, A. \& FEUILLADE, R. Genetic diversity of Ralstonia solanacearum race 3 in western Europe determined by AFLP, RC-PFGE and Rep-PCR. In: Prior, P., Allen, C. \& Elphinstone, J. (Eds.) Bacterial Wilt Disease: molecular and ecological aspects. Berlin: Springer - Verlang, INRA Reports. 1998. pp.44-49.

YUI, M., MONMA, S., HIRAI, M., NISHIMURA, S., UKAI, Y. \& ENOMOTO, S. Random amplified polymorphic DNA (RAPD) markers for the selection of the tomatoes resistant to bacterial wilt. Bulletin of the National Research Institute of Vegetables, Ornamental Plants and Tea 14:189-198. 1999. 